\title{
Clonal recruitment and somatic mutation in the generation of immunological memory to the hapten NP
}

\author{
Ana Cumano and Klaus Rajewsky \\ Institute for Genetics, University of Cologne, Weyertal 121, D-5000 \\ Cologne 41, FRG \\ Communicated by K. Rajewsky
}

The nucleotide sequences of the variable regions of $\lambda 1$ chain bearing anti-NP antibodies from the secondary response of $\mathrm{C57BL} / 6$ mice were determined. The data indicate that the V186.2 $V_{H}$ gene which dominates the primary anti-NP response is expressed in nine out of 10 secondary response antibodies and is extensively mutated. In the $V \lambda 1$ regions somatic mutations are less frequent. While point mutations predominate, there is suggestive evidence for two conversion events, one involving a one-codon deletion. Most, but not all, secondary response antibodies have a higher affinity (up to 10-fold) for the hapten than is seen in the primary response. The increase in affinity correlates with 'parallel' mutations in CDRs of $H$ and $L$ chains, likely to play a role in hapten binding. The analysis of $\mathrm{VDJ}_{\mathbf{H}}$ rearrangements demonstrates that the secondary response $\lambda 1$ chain-bearing antibodies are produced by a diverse set of $B$ cell clones, which are only rarely expressed in primary responses. These clones are characterized by $\mathrm{N}$-sequence-mediated heterogeneity in the $3^{\prime}$ half of CDR3, where the germ line sequence of the $D$ element DFl16.1 predominates in primary response antibodies. The antibodies analyzed in this and in previous work were isolated from idiotypically suppressed mice in order to evaluate whether, intraclonally, idiotype suppression selects antibody mutants into the memory pool, through suppression of the wild-type. A selection of this type was not detectable. However, idiotype suppression may control the pattern of clonotypes expressed in the primary versus the secondary response. Key words: affinity maturation/clonal selection/idiotypic control/ immunological memory/somatic mutation

\section{Introduction}

The $\mathrm{V}$ regions of primary response antibodies are often encoded by germ line genes, whereas the genes encoding antibodies of secondary and hyperimmune responses are usually extensively mutated (Gearhart et al., 1981; Bothwell et al., 1981, 1982; Griffiths et al., 1984; Sablitzky and Rajewsky, 1984; McKean et al., 1984; Cumano and Rajewsky, 1985; Wysocki et al., 1986). In addition, a broader range of antibody $V$ genes is expressed in secondary as compared with primary responses (Reth et al., 1978; Berek et al., 1985). Considering that somatic mutations accumulate in B cell clones at a high rate in a stepwise manner during proliferation (McKean et al., 1984; Rudikoff et al., 1984; Sablitzky et al., 1985a,b), a picture emerges in which B memory cells are generated through a distinct pathway of differentiation. This pathway is characterized by extensive proliferation in the absence of differentiation into plasma cells, somatic mutation and selection of cells expressing high affinity antibodies. Since the development of B cell memory is usually observed in
T cell-dependent responses, the hypothetical pathway of memory $\mathrm{B}$ cell differentiation could be controlled by regulatory $\mathrm{T}$ cells.

The primary antibody response to the hapten 4-hydroxy-3-nitrophenylacetyl (NP) coupled to the T cell-dependent carrier chicken gamma globulin (CG) is dominated in C57BL/ 6 mice by $\lambda 1$ chainbearing antibodies (Jack et al., 1977; Mäkelä and Karjalainen, 1977) expressing the V186.2 $\mathrm{V}_{\mathrm{H}}$ gene together with the DFl16.1 D segment (Bothwell et al., 1981; Cumano and Rajewsky, 1985). V186.2 is a $V_{H}$ gene of group 1 in the classification of Dildrop (1984). In secondary and hyperimmune responses to NP, however, the average affinity of the antibodies increases and a shift to $\varkappa$ chain-bearing antibodies is observed, although antibodies with $\lambda 1$ chains are still present (Reth et al., 1978). In the present study we ask whether the latter antibodies represent the somatically mutated progeny of the primary response antibodies. Specifically, we investigate whether regulatory $\mathrm{T}$ cells recognizing idiotypic determinants of those antibodies are involved in the selection of somatic antibody mutants into the memory compartment.

\section{Results}

Serological analysis of antibodies derived from a secondary anti$N P$ response in idiotypically suppressed C57BL/6 mice

When newborn C57BL/6 mice receive a single injection of antiidiotypic antibodies recognizing certain idiotopes associated with primary response anti-NP antibodies, they develop a state of chronic idiotype suppression which is at least partly controlled

Table I. Serological characterization of monoclonal secondary response anti-NP antibodies from idiotypically suppressed C57BL/6 mice

\begin{tabular}{llll}
\hline Hybridoma $^{\mathrm{a}}$ & Ac38 $^{\mathrm{b}}$ & Ac146 $^{\mathrm{b}}$ & Isotype \\
\hline 3B62 & $-{ }^{\mathrm{c}}$ & - & IgG1 $(\lambda 1)$ \\
3B44 & - & - & IgG1 $(\lambda 1)$ \\
3A183 & $+^{\mathrm{c}}$ & - & IgG1 $(\lambda 1)$ \\
3A112 & - & - & IgG1 $(\lambda 1)$ \\
3D61 & + & - & IgG1 $(\lambda 1)$ \\
3B5 & - & - & IgG1 $(\lambda 1)$ \\
3C13 & + & - & IgG1 $(\lambda 1)$ \\
$3 \mathrm{C} 52^{\mathrm{d}}$ & - & - & IgG1 $(\lambda 1)$ \\
C32 $^{\mathrm{d}}$ & - & - & IgG1 $(\lambda 1)$ \\
B423 $^{\text {d }}$ & - & - & IgG1 $(\lambda 1)$ \\
\hline
\end{tabular}

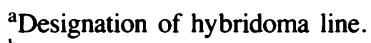

${ }^{b}$ Ac38 and Ac146 are idiotypic markers recurrently expressed in the anti-NP response of C57BL/6 mice and defined by monoclonal anti-idiotope antibodies (Reth et al., 1979). Subset $a$ antibodies (see text) are defined by co-expression of the two idiotopes (Takemori and Rajewsky, 1984).

$c_{+}$means binding of antibody to anti-idiotope coated plates under saturating conditions $50 \%$ of high control, determined by ELISA. - means binding under the same conditions $2 \%$ of high control. The high control was antibody NIG9 (Cumano and Rajewsky, 1985) which carries the V region against which the anti-adiotope antibody were raised. At concentrations of $\sim 10 \mu \mathrm{g} / \mathrm{ml}$ plateau binding was obtained in all cases.

${ }^{\mathrm{d}}$ These four hybridomas were isolated from one mouse, and the other six hybridomas from another mouse. 
Table II. Relative affinities of secondary and primary anti-NP antibodies to NP and NIP

\begin{tabular}{|c|c|c|}
\hline & K.NIP $(\mu \mathrm{M})$ & K.NP $(\mu \mathrm{M})$ \\
\hline \multicolumn{3}{|c|}{$\underline{\text { Primary immune response }}$} \\
\hline B1- $8^{\mathrm{a}}$ & 0.1 & 2.0 \\
\hline N1G9a & 0.1 & 2.0 \\
\hline $\mathrm{N} 1 \mathrm{C} 12^{\mathrm{a}}$ & 0.5 & 2.5 \\
\hline S2E9 $9^{b}$ & 0.1 & 0.95 \\
\hline $\mathrm{S} 1 \mathrm{~F} 12^{\mathrm{b}}$ & 0.1 & 2.0 \\
\hline $\mathrm{S} 2 \mathrm{G} 7^{\mathrm{b}}$ & 0.1 & 2.0 \\
\hline $\mathrm{S} 1 \mathrm{~F} 2^{\mathrm{b}}$ & 0.5 & 2.2 \\
\hline S2D8 ${ }^{b}$ & 0.8 & 3.0 \\
\hline $\mathrm{S} 2 \mathrm{H} 5^{\mathrm{b}}$ & 1.0 & 3.6 \\
\hline \multicolumn{3}{|c|}{ Secondary immune response } \\
\hline $3 \mathrm{~B} 62$ & 0.016 & 0.5 \\
\hline 3B44 & 0.02 & 0.5 \\
\hline $3 \mathrm{~A} 183$ & 0.02 & 0.9 \\
\hline $3 \mathrm{~A} 112$ & 0.03 & 0.8 \\
\hline 3D61 & 0.03 & 0.6 \\
\hline 3B5 & 0.03 & 1.0 \\
\hline $3 \mathrm{C} 13$ & 0.5 & 5.4 \\
\hline $3 \mathrm{C} 52$ & 1.0 & 8.0 \\
\hline $\mathrm{C} 32$ & 0.06 & 0.8 \\
\hline B23 & 0.015 & 0.4 \\
\hline
\end{tabular}

aPrimary response antibodies from control mice.

bPrimary response antibodies from idiotypically suppressed mice (Cumano and Rajewsky, 1985).

by regulatory $\mathrm{T}$ cells. This state is defined by the absence, in the primary anti-NP response, of an idiotypically defined subset of anti-NP antibodies (subset $a$ ) recurrently expressed in the antiNP response of untreated animals (Takemori and Rajewsky, 1984).

Through sequence analysis of primary response antibodies in normal and idiotypically suppressed mice, we have previously identified the structural correlate of the idiotypic specificity of subset $a$ : a TACG sequence at the border of the V186.2 $\mathrm{V}_{\mathrm{H}}$ region and the DFl16.1 segment, resulting in the 'insertion' of an aspartic acid into a stretch of three germ-line-encoded tyrosines (Cumano and Rajewsky, 1985).

In this study, 15-week-old idiotypically suppressed mice were primed with $100 \mu \mathrm{g}$ alum-precipitated NP-CG. Serum collected from the animals 12 days after immunization contained high titers of anti-NP antibodies, but none of subset $a$ (data not shown). Five weeks after priming, the animals received $20 \mu \mathrm{g} \mathrm{NP}-\mathrm{CG}$, a dose which does not elicit an immune response in naive mice. Three days later, the mice were bled out and the spleen cells of two animals were separately fused to X63. Ag8.653 myeloma cells. The sera again contained large amounts of anti-NP antibodies, but the idiotypic markers of subset $a$ were still undetectable (data not shown). Ten hybridomas secreting $\lambda 1$ chain-bearing, NP-binding antibodies, four from one and six from another mouse, were randomly selected from 180 hybridomas secreting such ( $\lambda 1$ chain-bearing) antibodies. Table I shows the isotypes and idiotypic specificity of these 10 antibodies. All antibodies belong to the IgG1 class and none bears the idiotypic marker characteristic for subset $a$. This marker was not detected in any of the remaining 170 hybridomas (data not shown). Table II shows the relative affinities of the 10 antibodies for the haptens NP and NIP (4-hydroxy-3-nitro-5-iodo-phenylacetyl) to which the antibodies bind more strongly than to NP itself, similar to primary response antibodies ('heteroclicity'; Imanishi and Mäkelä, 1973). The relative affinities of some primary response antibodies are given for comparison. As expected, most of the secondary response antibodies exhibit 5- to 10-fold higher affinity than antibodies from the primary response. However, there are two notable exceptions: antibodies 3C13 and 3C52 bind NP with a lower affinity than all primary response antibodies.

\section{Sequence analysis of the secondary response antibodies}

The sequences encoding the $\mathrm{VJ}$ regions of the $\lambda 1$ chains of the 10 secondary response hybridomas are shown in Figure 1, with the germ line $V \lambda 1$ sequence (Blomberg and Tonegawa, 1978) given as a reference. Five of the 10 sequences are unmutated; the other sequences carry between one and three point mutations. Of a total of eight point mutations six are replacement mutations, and of these five are located in complementarity determining regions (CDR1 and CDR2) (Table II). That this is due to selection is underlined by the finding that four chains carry an identical mutation in position 57, changing a $\mathrm{C}$ to a $\mathrm{T}$ and, at the amino acid level, an alanine to a valine.

The sequences encoding the $\mathrm{VDJ}_{\mathrm{H}}$ regions of the secondary response antibodies appear in Figure 2. The $V_{H}$ gene V186.2 and the DFl16.1 segment (both dominating the primary anti-NPresponse) are given as reference sequences, together with $\mathrm{J}_{\mathrm{H}} 2$.

All antibodies except $\mathrm{B} 423$ express $\mathrm{V}_{\mathrm{H}}$ genes which are strongly homologous to $\mathrm{V} 186.2$. The $\mathrm{V}_{\mathrm{H}}$ region of antibody B423 differs from V186.2 by 49 nucleotides and has $90 \%$ homology to another $\mathrm{V}_{\mathrm{H}}$ gene of the same group (V130) isolated by Bothwell (1984). The other nine $V_{H}$ regions differ from V186.2 at a minimum of two and a maximum of 12 nucleotide substitutions (Table III). Both silent and replacement substitutions are seen in relation to the reference sequence, and the replacement substitutions are concentrated in CDR1 and CDR2. As in the case of the $V_{L}$ regions, parallel mutations are seen in several positions, leading to the same amino acid change either by the same (positions 26, 33, 38, 61, 64 and 66) or by different nucleotide substitutions (positions 35 and 84). Four of these positions are in CDRs. A search among all available $V_{H}$ sequences revealed that (i) 20 out of the 50 substitutions are not found in any other known $\mathrm{V}_{\mathrm{H}}$ gene sequence of group 1 , and (ii) if a substitution is found in another sequence, that sequence differs from the one carrying the substitution in many more positions than the V186.2 gene. In addition, there are only two cases (boxed in Figure 2) where more than one substitution seen in a given sequence is also present in another $\mathrm{V}_{\mathrm{H}}$ sequence. Finally, all nine V186.2- related sequences carry, in positions 74 and 75 , codons which had so far only been seen in those positions in V186.2. Together with the Southern blot analysis (see below) and a positive correlation between mutations in $\mathrm{V} \lambda 1$ and divergence from the V186.2 sequence (Table III), these findings lead to the conclusion that the $\mathrm{V}_{\mathrm{H}}$ regions of nine out of $10 \lambda 1$ chain-bearing secondary response antibodies express a somatically mutated V186.2 gene.

The two cases in which multiple substitutions are shared between a $V_{H}$ gene in Figure 2 and a known $V_{H}$ gene of group 1 are of particular interest since they may represent gene conversion events (see Discussion).

The CDR3s of the $\mathrm{H}$ chains exhibit pronounced heterogeneity, although several of them (3B5, C32, 3A183, 3C13, 3B44) may express sequences of the DFl16.1 segment (Kurosawa and Tonegawa, 1982). Sequence heterogeneity is particularly pronounced at the $\mathrm{D}-\mathrm{J}_{\mathrm{H}}$ border where the joining process has generated $\mathrm{N}$ sequences in most clones. Somatic mutations may have introduced 

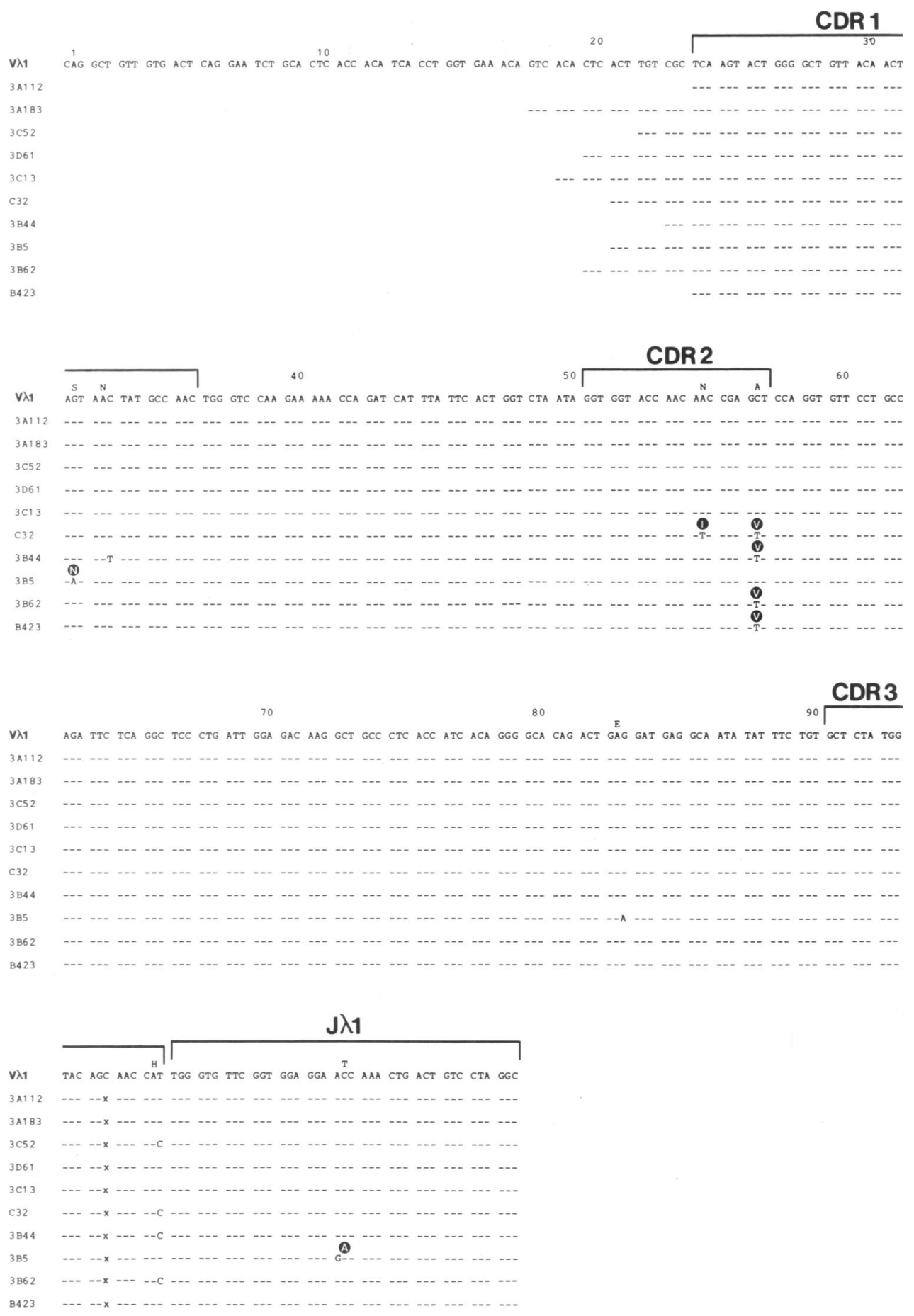

Fig. 1. Nucleotide sequences of the $V \lambda$ regions expressed in the hybridomas 3B62, 3B5, 3B44, C32, 3C13, 3D61, 3C52, 3A183, 3A112 and B423. The sequences are compared with $\mathrm{V} \lambda 1$ and $\mathrm{J} \lambda \mathrm{I}$ germ line sequences. Nucleotides identical to the reference sequence are indicated by dashes, sequence ambiguities by $x$. Marked in black circles are the amino acid substitutions relative to the reference sequence.

additional variability. The antibodies express $\mathrm{J}_{\mathrm{H}} 1,2,3$ or 4 , and in the $\mathrm{J}_{\mathrm{H}}$ segment somatic mutations are present only in positions belonging to CDR3.

The sequences of the $\mathrm{D}$ and $\mathrm{J}_{\mathrm{H}}$ regions establish that all 10 secondary response antibodies in Figures 1 and 2 are products of different $B$ cell clones. (Two further secondary response antibodies whose sequences were identical to those of antibodies $3 \mathrm{~A} 112$ and $3 \mathrm{~A} 183$, respectively, and which also came from the same fusion experiment as the latter antibodies are eliminated from the analysis. These 'repeat' clones may or may not have arisen in vitro, after cell fusion.) None of these clones could have originally produced an antibody of subset $a$ for which the mice were idiotypically suppressed: subset $a$ antibodies are characterized structurally by a TACG sequence at the $\mathrm{V}_{\mathrm{H}}-\mathrm{D}$ border, in front of the DFl16.1 element (Cumano and Rajewsky, 1985).

Restriction analysis of the $V D J_{H}$ loci of the secondary response antibodies

To confirm that the V186.2 gene is indeed expressed in most of the 10 secondary response antibodies, genomic DNA was pre- 

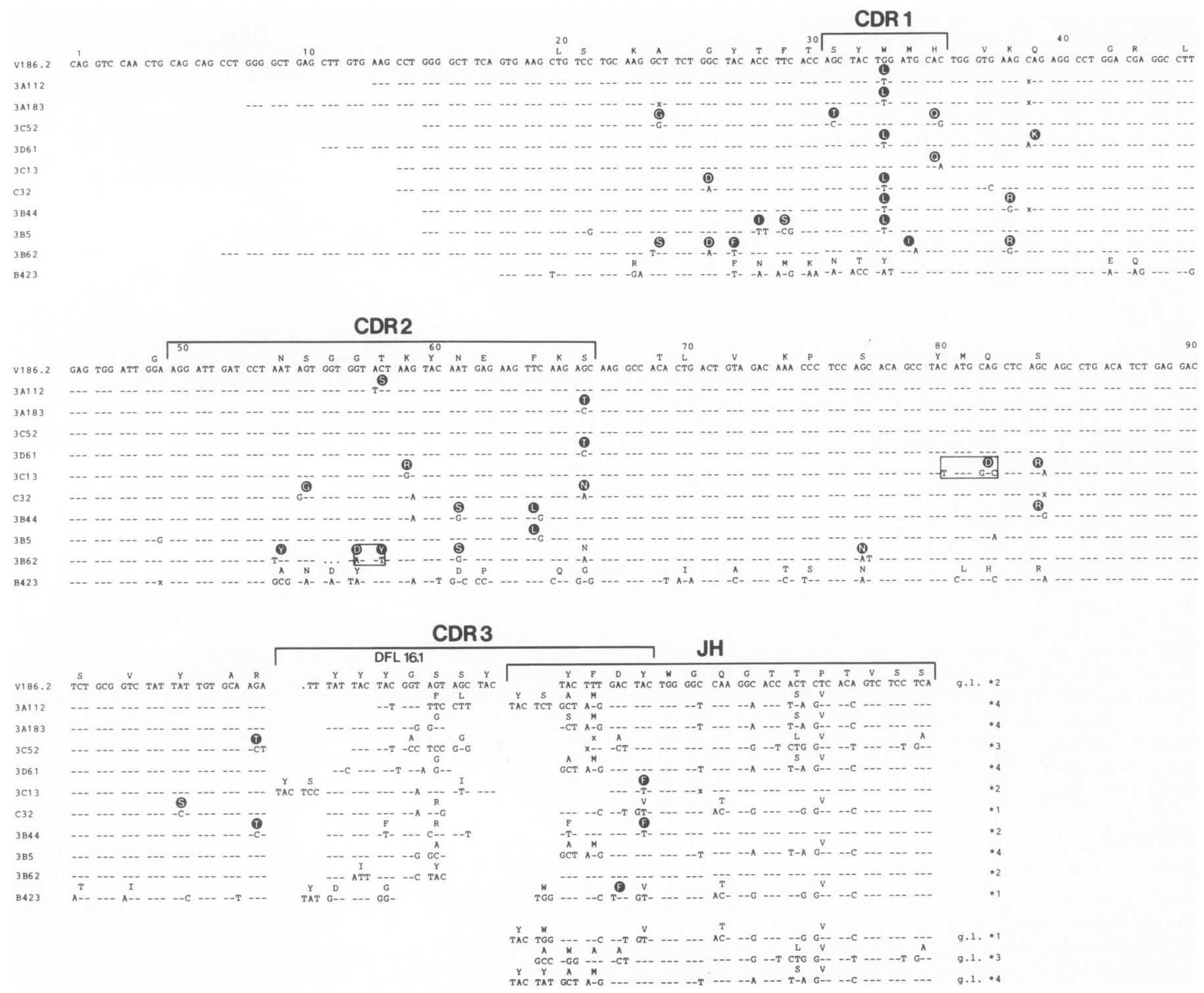

Fig. 2. Nucleotide sequences of the $\mathrm{VDJ}_{\mathrm{H}}$ regions of the hybridomas 3B62, 3B5, 3B44, C32, 3C13, 3D61, 3C52, 3A183, 3A112 and B423. The sequences are compared with the germ line $\mathrm{V} 186.2$ gene, the DFl16.1 segment and the $\mathrm{J}_{\mathrm{H}} 2$ gene. Nucleotides identical to the reference sequence are indicated by dashes, sequence ambiguities by $x .{ }^{*}$ indicates the $\mathrm{J}_{\mathrm{H}}$ gene expressed by the antibodies. Marked in black circles are the amino acid substitutions relative to the reference sequence in antibodies expressing the V186.2 gene. The segments involved in putative gene conversion events are boxed. CDR, complementary determining region; gl, germ line.

pared from seven of the hybridomas, cut with restriction enzymes and subjected to Southern blot analysis, using a probe complementary to sequences downstream of the $\mathrm{J}_{\mathbf{H}}$ locus (BoerschSupan et al., 1985) to identify rearranged $\mathrm{VDJ}_{\mathrm{H}}$ loci. DNA from the hybridoma B1-8, and the fusion partner X63.Ag8.653 served as controls. The results obtained after digestion with the enzyme $E c o$ RI are shown in Figure 3. A single band of $6.4 \mathrm{~kb}$ is seen in the case of cell line X63.Ag8.653 (lane 8), as reported earlier (Sablitzky et al., 1982). A similar band appears in the case of most of the other cells. The hybridoma B1-8 expresses the V186.2 $\mathrm{V}_{\mathrm{H}}$ gene in combination with $\mathrm{J}_{\mathrm{H}} 2$ (Bothwell et al., 1981), represented by a 4.3-kb band (lane 9) (Sablitzky et al., 1982). A similar band is seen in the case of the hybridomas 3B62 and 3B44 (lanes 5 and 7), consistent with the expression of V186.2 and $\mathrm{J}_{\mathrm{H}} 2$ in these cells (Figure 2; an additional band seen in these and other cases corresponds to the rearranged non-expressed $\mathrm{VDJ}_{\mathrm{H}}$ locus present in the cells). The hybridomas 3D61, 3A112 and 3B5 are assumed to express V186.2 in combination with $\mathrm{J}_{\mathrm{H}} 4$. A 3.3-kb band is expected for this rearrangement and is found in all three cases (lanes 3,4 and 6). Rearrangement of V186.2 to $\mathrm{J}_{\mathrm{H}} 3$ would generate a $4.0-\mathrm{kb}$ band which is found in the case of hybridoma 2C52 (lane 2). Only one of the 10 secondary response antibodies was identified by sequence analysis as not expressing the V186.2 gene. Indeed, restriction analysis of the DNA from this hybridoma (B423, lane 1) reveals two bands (7.8 and $5.2 \mathrm{~kb}$ ) not predicted for any productive rearrangement of the V186.2 gene (this hybridoma has lost the $\mathrm{VDJ}_{\mathbf{H}}$ locus of the fusion partner). Further restriction analysis was carried out with the restriction enzymes $\mathrm{XbaI}$ and HindIII (data not shown). As in the case of EcoRI, the results were consistent with our con- 
Table III. Silent and replacement mutations in the heavy and light chain variable regions of secondary anti-BP antibodies expressing the V186.2 gene

\begin{tabular}{|c|c|c|c|c|c|c|c|c|}
\hline & \multicolumn{4}{|c|}{ Heavy chain $^{a}$} & \multicolumn{4}{|c|}{ Light chain $^{\mathrm{a}}$} \\
\hline & \multicolumn{2}{|c|}{ CDR } & \multicolumn{2}{|l|}{ FR } & \multicolumn{2}{|c|}{ CDR } & \multicolumn{2}{|c|}{ FR } \\
\hline & $\mathrm{R}$ & $S$ & $\mathbf{R}$ & $S$ & $\mathbf{R}$ & $S$ & $\mathbf{R}$ & $S$ \\
\hline 3B62 & 6 & 0 & 5 & 1 & 1 & 0 & 0 & 0 \\
\hline 3B5 & 2 & 0 & 3 & 4 & 1 & 0 & 1 & 1 \\
\hline 3B44 & 4 & 1 & 2 & 1 & 1 & 1 & 0 & 0 \\
\hline $3 \mathrm{C} 32$ & 3 & 1 & 2 & 1 & 2 & 0 & 0 & 0 \\
\hline $3 \mathrm{C} 13$ & 3 & 0 & 3 & 1 & 0 & 0 & 0 & 0 \\
\hline 3D61 & 2 & 0 & 1 & 0 & 0 & 0 & 0 & 0 \\
\hline $3 \mathrm{C} 52$ & 2 & 0 & 1 & 0 & 0 & 0 & 0 & 0 \\
\hline $3 \mathrm{~A} 183$ & 2 & 0 & 0 & 0 & 0 & 0 & 0 & 0 \\
\hline \multirow[t]{2}{*}{$3 \mathrm{~A} 112$} & 2 & 0 & 0 & 0 & 0 & 0 & 0 & 0 \\
\hline & 26 & 2 & 17 & 8 & 5 & 1 & 1 & 1 \\
\hline
\end{tabular}

Ratio of silent/replacement mutations

\begin{tabular}{lllll}
\hline & CDR & Expected $^{\mathrm{b}}$ & FR & Expected $^{\mathrm{b}}$ \\
\hline Heavy chain & $1 / 13$ & $1 / 6$ & $1 / 2$ & $1 / 3.1$ \\
Light chain & $1 / 5$ & $1 / 3.5$ & $1 / 1$ & $1 / 2.7$ \\
\hline
\end{tabular}

${ }^{a}$ The calculations do not include possible nucleotide exchanges in the $\mathrm{D}$ region and in $\mathrm{VH}-\mathrm{D}, \mathrm{D}-\mathrm{JH}$ and $\mathrm{V} \lambda 1-\mathrm{J} \lambda 1$ joining regions.

${ }^{b}$ Calculated from the nucleotide composition of the V186.2 and the V $\lambda 1$ gene. $R$, replacement mutation; $S$, silent mutation; CDR, complementary determining region; FR, framework region.

clusion from the sequence analysis, namely that the secondary response antibodies, excluding antibody B423, express the V186.2 $\mathrm{V}_{\mathrm{H}}$ gene.

\section{Discussion}

Most $\lambda I$ chain-bearing anti-NP antibodies from the secondary response express the V186.2 gene in somatically mutated form In previous work (Bothwell et al., 1981), a $\lambda 1$ chain-bearing antiNP antibody produced by a hyperimmune C57BL/6 mouse was analyzed and appeared to express the $\mathrm{V} 186.2 \mathrm{~V}_{\mathrm{H}}$ gene as most primary response anti-NP antibodies (Cumano and Rajewsky, 1985), but the gene carried 10 somatic point mutations. The identification of any particular $\mathrm{V}_{\mathrm{H}}$ gene as a somatic mutant of V186.2 is complicated by the fact that the latter belongs to the largest $V_{H}$ gene group [group 1 in the classification of Dildrop (1984)]. However, this problem has been largely overcome because a large number of group $1 \mathrm{~V}_{\mathbf{H}}$ sequences is now known (see Dildrop, 1984; and Schiff et al., 1985; Bothwell, 1984; Sablitzky and Rajewsky, 1984; Sablitzky et al., 1985a; Maizels and Bothwell, 1985; R.Dildrop and M.Siekevitz, unpublished results) and because a series of randomly picked hybridomas was analyzed in terms of both $V_{H}$ gene rearrangement and nucleotide sequence of the expressed $V_{H}$ and $V_{L}$ genes. By doing so we can identify the expressed $V_{H}$ genes as somatic mutants of $\mathrm{V} 186.2$ on the basis of the following pieces of evidence: (i) sequence homology to V186.2, which is closer to this gene than to any other known $\mathrm{V}_{\mathrm{H}}$ gene and includes the 'diagnostic' positions 74 and 75; (ii) pattern of substitutions, of which one-third is not found in any other known gene of the family and which, with two exceptions, do not occur in the same combination in any other known $V_{H}$ sequence; (iii) positive correlation between number of substitutions in $\mathrm{V}_{\mathrm{H}}$ and $\mathrm{V}_{\mathrm{L}}$; (iv) consistency of the

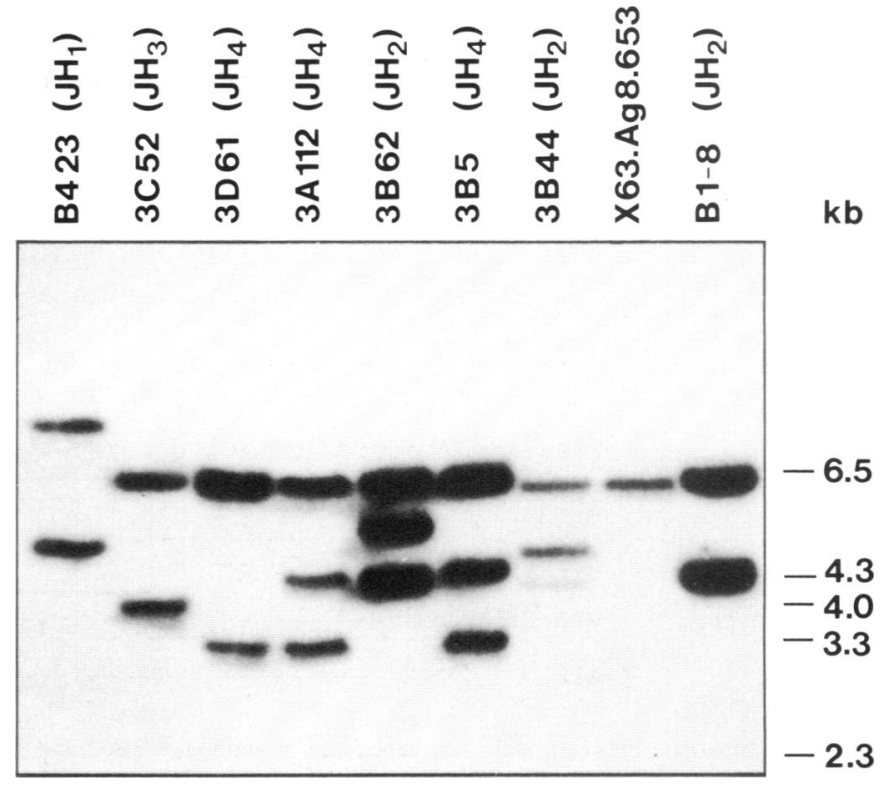

Fig. 3. Southern blot analysis of cell lines B423, 3C52, 3D61, 3A112, 3B62, 3B5, 3B44, the fusion partner X63.Ag8.653 and B1-8. Genomic DNA was digested with EcoRI, electrophoresed, blotted and hybridized with a $J_{\mathbf{H}}$ specific probe $\left(J_{\mathrm{H}} 3-4\right.$ probe $)$.

restriction analysis with the predictions of V186.2 rearrangements to different $J_{\mathbf{H}}$ segments. By these criteria the majority of the secondary response antibodies, presumably nine out of 10 , express a somatically mutated V186.2 gene.

\section{Gene conversion may contribute to somatic antibody diversif-} cation

Most of the nucleotide exchanges in the genes encoding the secondary response $\mathrm{V}$ regions appear to represent point mutations. However, in two cases more than one of the substitutions was detected in a given $V_{H}$ gene (Figure 2) in another known $V_{H}$ sequence (excluding the sequences in Figure 2) in the same positions. Significantly, both repeats involved substitutions in close vicinity (Figure 4). In the first, one (silent) nucleotide substitution in codon 80 and two substitutions in codon 82 (i.e. in the third framework) are shared between the $\mathrm{V}_{\mathrm{H}}$ genes of antibody 3C13 (Figure 2) and antibody A31.90 (Sablitzky and Rajewsky, 1984). Another closely related antibody (A25.9) shares two of the three substitutions. The $\mathrm{V}_{\mathrm{H}}$ gene of $\mathrm{A} 31.90$ differs from the V186.2 gene in 55 positions. The situation could be obscured by somatic mutation of the A31.90 and A25.9 antibodies. However, Blankenstein et al. (1984) have isolated a non-rearranged $\mathrm{V}_{\mathrm{H}}$ gene of BALB/c origin (VAR36) which carries two of the three substitutions in codons 80 and 82 and is strongly homologous to the $A 31.90 \mathrm{~V}_{\mathrm{H}}$ gene. The second case of shared substitutions involves the $V_{H}$ gene of antibody 3B62, the only gene in the collection carrying a deletion (codon 56). Downstream of this deletion, in codons $\mathbf{5 7}$ and 58, two nucleotide substitutions are seen which are also found in the germ line $\mathrm{V}_{\mathrm{H}}$ gene $\mathrm{H} 17$ isolated by Schiff et al. (1985) from the BALB/c genome. Overall, the $\mathrm{V}_{\mathrm{H}}$ genes $\mathrm{H} 17$ and V186.2 differ from each other by 44 nucleotides. Codon 56 is the upstream border of a region of particularly strong homology. It is flanked in $\mathrm{H} 17$ by a short palindrome around codon 53 (pos. 51, 52, 54, 55) which could have promoted a conversion event (Krawinkel et al., 1986). The 
V186.2 AGG ATT GAT CCT AAT AGT GGT GGT ACT AAG TAC AAT GAG AAG TTC AAG GGC

$3 \mathrm{~B} 62$

H1 7

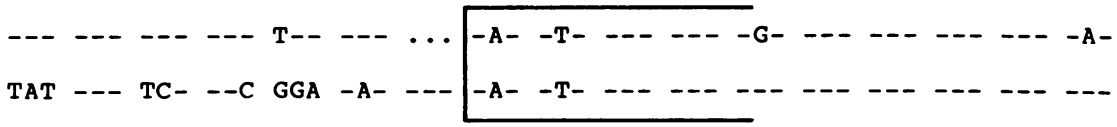

80

90

V186.2 CCC TCC AGC ACA GCC TAC ATg CAG CTC AGC AGC CTG ACA TCT GAG GAC

$3 \mathrm{C} 13$

A 31.90

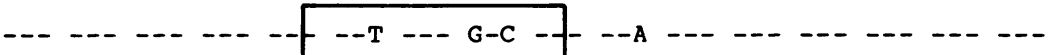

VAR 36

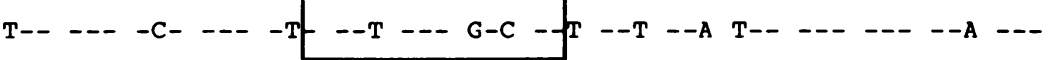

A25. 9

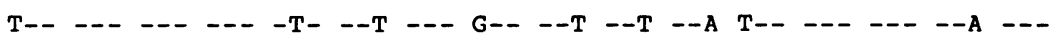

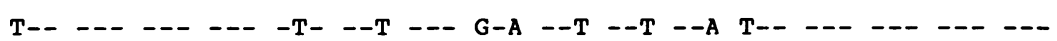

Fig. 4. Comparison between nucleotide sequences of antibodies $3 \mathrm{~B} 62$ and $3 \mathrm{C} 13$ and the germ-line genes acting as putative donors in a gene conversion event. The sequence of H17 was taken from Schiff et al. (1985). the sequence of VAR36 was taken from Blankenstein et al. (1982). The sequences of A31.90 and A25.9, two antibodies from C57BL/6 mice which express the VAR36 gene, are also shown. The nucleotides involved in gene conversion are boxed.

deletion at codon 56 could have occurred in the process of mismatch repair (Szostock et al., 1983). The downstream border of the conversion cannot be determined with accuracy since the C57BL/6 counterpart of $\mathrm{H} 17$ has not yet been isolated and somatic point mutations have occurred in the 3B62 sequence.

A case of mitotic gene conversion between $V_{H}$ genes in a hybridoma line has been reported previously (Dildrop et al., 1982; Krawinkel et al., 1983). In addition, there is a strong indication that mitotic gene conversion plays a major role in the somatic diversification of antibodies in the chicken (Reynaud and Weill, 1985; and personal communication). The present data suggest that it may also contribute to somatic antibody diversification in the mouse, to a limited extent.

Replacement and silent mutations are more frequent in the rearranged V186.2 than in the rearranged $V \lambda l$ gene

The analysis in Table II demonstrates that somatic mutations are less frequently observed in the $V_{L}$ than the $V_{H}$ regions, by a factor of 7 for replacement and of 5 for silent mutations. It therefore appears that the mechanism of somatic hypermutation is less active in the rearranged $V \lambda 1$ as compared with the rearranged V186.2 gene. This could represent a V gene or a locus-specific difference. The finding of extensive somatic mutation in several $\mathrm{V}_{\mathrm{H}}$ and also $\mathrm{V} \varkappa$ genes (Pech et al., 1981; McKean et al., 1984; Griffiths et al., 1984; Sablitzky et al., 1985a) is in accord with the latter possibility.

Distribution of silent and replacement mutations in frameworks suggests that every fourth mutation randomly introduced into a rearranged V186.2 gene is deleterious for the V domain

The 12 silent mutations identified in the present collection of sequences (Table III) show a distribution over CDRs and frameworks proportional to their physical length, i.e. three (25\%) are in CDRs and nine (75\%) in frameworks. This result supports the view that the accumulation of replacement mutations in the CDRs (see below) is indeed due to cellular selection. For the frameworks, a ratio of replacement to silent substitutions of 2:1 (Table III) is found, in contrast to 2.9:1 as would be predicted for the V186.2 gene in a model of random mutation. The same tendency has been observed in other systems of somatic mutation (Griffiths et al., 1984; Berek et al., 1985; Sablitzky et al., 1985a;
Clark et al., 1985) and when related $\mathrm{V}_{\mathrm{H}}$ genes in the germ line were compared (Loh et al., 1983. Blankenstein et al., 1984). The 2:1 ratio is interpreted to mean that roughly one-third of the possible replacement mutations in the V186.2 framework are incompatible with the overall three-dimensional structure of the $\mathrm{V}$ domain, which is guaranteed by the $\beta$ sheets of the frameworks (see Novotny and Haber, 1985). Therefore, since (i) the frameworks constitute around $75 \%$ of the $\mathrm{V}_{\mathrm{H}}$ domain, (ii) replacement mutations in CDRs lead to the collapse of the $\mathrm{V}$ domain less frequently (see Ohno et al., 1985) and (iii) nonsense mutations (5\%) have also to be considered, it is concluded that $\sim 25 \%$ of all mutations in the rearranged V186.2 gene are 'lethal' for the antibody and cells carrying such mutations will consequently be lost from the system. Even at a rate of 0.5 mutations per cell per generation such losses would not seriously affect $B$ cell clone sizes.

\section{Selection for replacement mutations in CDRs}

The replacement substitutions found in the nine antibodies (Table II) are preferentially localized in the CDRs (31 out of 49 , the CDRs representing roughly $25 \%$ of the total sequence). This is in general agreement with the data from the other systems, although the preference is not always seen in both $\mathrm{H}$ and $\mathrm{L}$ chains as in the present case. In addition, the rate of replacement to silent substitutions is 13:1 in CDRs 1 and 2 of the V186.2 gene. This ratio is significantly higher than the $6: 1$ ratio expected on the basis of random mutation in these CDRs. The discrepancy between the calculated and the observed ratio suggests that a minimum of $50 \%$ of the somatic replacement mutations in CDRs 1 and 2 were subject to selection, presumably of the cells expressing them. The stringency of this selection process is evident from the fact that, of the 26 replacement mutations seen in CDRs 1 and 2, 11 (close to 50\%) generate an amino acid substitution which is found in one or more other secondary response antibodies in the same position, through the same or a different nucleotide exchange (parallel mutations, Figure 2).

It is likely that some of the somatic mutations seen contribute to more efficient hapten binding, since most secondary anti-NP antibodies have a higher affinity for the hapten than antibodies from the primary response (Table II). An example is position 


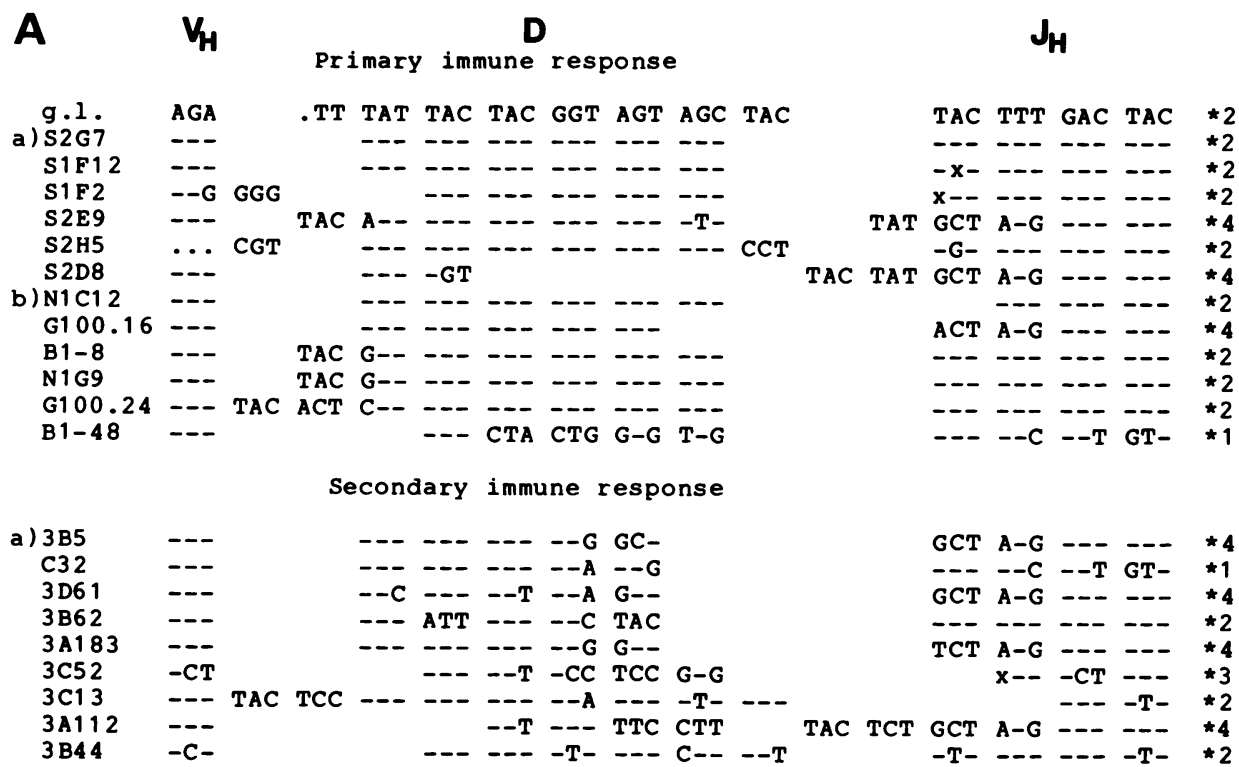

B

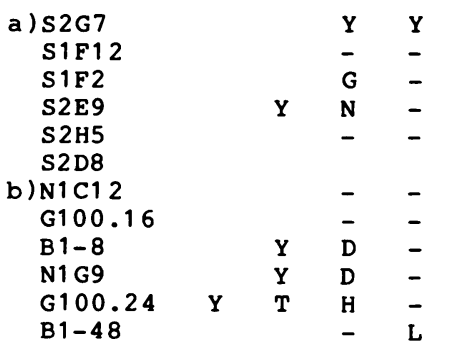

Primary immune response

$$
\begin{aligned}
& \text { a) } 3 \text { B5 } \\
& \text { C32 } \\
& 3 \mathrm{D} 61 \\
& 3 \mathrm{~B} 62 \\
& 3 \mathrm{~A} 183 \\
& 3 \mathrm{C} 52 \\
& 3 \mathrm{C} 13 \\
& 3 \mathrm{~A} 112 \\
& \text { 3B44 }
\end{aligned}
$$

$\begin{array}{lllllllll}\text { Y } & \text { G } & \text { S } & \text { S } & \text { Y } & \text { F } & \text { D } & \text { Y } & \\ - & - & - & - & \text { X } & - & - & - & \\ - & - & - & - & \text { X } & - & - & - & \\ - & - & - & \text { I } & - & \text { A } & \text { M } & \text { D } & \text { Y } \\ - & - & - & - & \text { P } & \text { C } & \text { F } & \text { D } & \text { Y } \\ & \text { Y } & \text { C } & \text { Y } & - & \text { A } & \text { M } & \text { D } & \text { Y } \\ - & - & - & - & \text { F } & \text { D } & \text { Y } & & \\ - & - & - & \text { T } & \text { M } & \text { D } & \text { Y } & & \\ - & - & - & - & - & - & - & - & - \\ - & - & - & - & - & - & - & - \\ - & - & - & - & - & - & - & - \\ \text { L } & - & \text { W } & \text { F } & \text { D } & \text { Y } & \end{array}$

\begin{tabular}{ccc|ccccc}
- & - & A & A & M & D & Y & \\
- & - & R & Y & F & D & V & \\
- & - & G & A & M & D & Y & \\
- & - & Y & Y & F & D & Y & \\
- & - & G & - & M & D & Y & \\
S & - & X & A & - & & & \\
- & - & - & I & - & D & F & \\
L & Y & - & A & M & D & Y & \\
V & S & R & Y & F & - & - & F
\end{tabular}

Fig. 5. Nucleotide (A) and deduced amino acids sequences (B) of CDR3 of anti-NP antibodies from primary and secondary responses in C57BL/6 mice. (a)

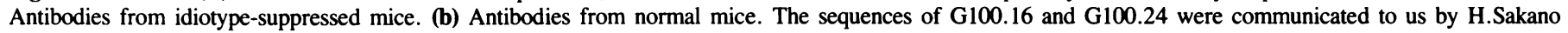
and K.Karjalainen. The B1-8 and B1-48 sequences are from Bothwell et al. (1981), and A.Bothwell (personal communication). The sequences of S2G7, S1F12, S1F2, S2E9, S2H5, N1C12 and N1G9 are taken from Cumano and Rajewsky (1985). S1 and S2 represent different donor mice. * indicates the $\mathrm{J}_{\mathrm{H}}$ gene expressed by the antibodies.

33 of the $\mathrm{H}$ chain in which a tryptophan is replaced by a leucine in six of 9 antibodies [Figure 2; note that this replacement had already been seen in antibody S43 studied by Bothwell $e t$ al. (1981), where it was generated by a substitution of two nucleotides]. Position 33 of the $\mathrm{H}$ chain is considered to be of key importance for antigen-binding specificity (Ohno et al., 1985), also in this particular system (Reth et al., 1981).

Antibodies 3C13 and 3C52 are distinguished from the others by their exceptionally low affinity (Table II), suggesting that the cells producing them had either not yet accumulated favorable mutations sufficiently or had been hit by an unfavorable mutation. With respect to the latter possibility there is evidence that somatic mutants which have lost antigen-binding specificity are generated upon priming with antigen (M.Siekevitz, R.Dildrop, C.Kocks and K.R., in preparation).
Different $B$ cell clones in primary and secondary anti-NP responses: primary response homogeneity versus secondary response heterogeneity

It is known that in the memory response to NP, B cell clones are selected which are not seen in the primary response, namely clones expressing high affinity $x$ chain-bearing antibodies (Reth et al., 1979). A similar phenomenon was also observed recently in the anti-oxazolone response (Berek et al., 1985). Together with previous evidence (Cumano and Rajewsky, 1985) the present data demonstrate that in the NP system the same holds true even when cells expressing the same $V_{H}$ and $V_{L}$ genes, namely $V \lambda 1$ and V186.2, are considered. The evidence is given in Figure 5, in which the CDR3s of the secondary response antibodies characterized in this paper are compared with those of primary response 
anti-NP antibodies from normal and idiotypically suppressed mice.

With few exceptions, the primary response antibodies express a germ line DFl16.1 element with little or no $\mathrm{N}$-sequence variability at its borders (Cumano and Rajewsky, 1985). In the secondary response antibodies, the $5^{\prime}$ half of CDR3 resembles that seen in the primary response. However, downstream of the germline-encoded stretch of tyrosines followed by a glycine, the sequences deviate from the germ-line-encoded Ser-Ser-Tyr/Phe sequence expressed in most primary response antibodies. The pronounced sequence heterogeneity seen in this area is best explained in most cases by the substitution of the 3 ' half of DFl16.1 (antibodies 3B5, C32, 3A183, 3C13 and 3B44) or DSp2 (antibodies $3 \mathrm{C} 52,3 \mathrm{~A} 112$ and $3 \mathrm{D} 61$ ) by $\mathrm{N}$ sequences generated in the $\mathrm{D}-\mathrm{J}_{\mathrm{H}}$ joining process. The structural distinction between primary and secondary response antibodies in CDR3 does not appear to be an artefact of individual variation, or to depend upon whether the animals were idiotypically suppressed [note the similarity of primary antibodies from normal and suppressed mice and of secondary antibodies produced by different suppressed mice; an anti-NP antibody from a non-suppressed hyperimmune C57BL/6 mouse, antibody S43, lacked DFl16.1 sequence altogether (Bothwell et al., 1981)]. However, antibodies fitting into the secondary response pattern are also represented as a minor fraction in the primary response (antibodies B1-48 and S2D8, Figure 5).

The data in Figure 5 is interpreted as follows: the germ line sequences of V186.2, DFl16.1 and a $\mathrm{J}_{\mathrm{H}}$ element, together with $\mathrm{VJ} \lambda 1$, encode NP-binding $\mathrm{V}$ regions which are most frequently expressed in the pre-immune repertoire, perhaps because they are the only germ-line-encoded $\mathrm{V}$ regions with a good affinity for the hapten. Hence, antibodies of this type, with minor variations at the borders of $\mathrm{D}$, dominate the primary response. However, other rearrangements of V186.2, involving substitution of part of the DFl16.1 sequence by $\mathrm{N}$ sequences, occasionally also result in NP specificity. At the $\mathrm{V}_{\mathrm{H}}-\mathrm{D}$ boundary, little variation is seen because the tyrosine in position 99 appears to be essential for NP binding (Reth et al., 1980; Cumano and Rajewsky, 1985; Boersch-Supan et al., 1985; and the present data). In contrast, towards the $\mathrm{D}-\mathrm{J}_{\mathrm{H}}$ boundary, sequences other than those encoded by the DFl16.1 element are permissible, although the length of CDR3 is not allowed much variation (average length 10, range $8-12$ amino acids in the primary and 9 , range $8-11$ in the primary response, Figure 5). Thus, through the substitution of $3^{\prime}$ sequences of DFl16.1 or related D elements by certain $\mathrm{N}$ sequences, NP binding antibodies not expressing the DFl16.1 germline sequence are also generated in the pre-immune repertoire. This heterogeneous set of antibodies represents a minor portion $(2 / 12)$ of the primary response, presumably because rearrangements of this type only rarely result in good NP-binding specificity. However, in the secondary response these antibodies dominate, together with $\varkappa$ chain-bearing antibodies. Antibodies bearing $x$ chains are also rare in the primary response, and antibodies of this type with reasonable affinity for the NP hapten appear to be expressed at very low frequency in the B cell population of non-immunized C57BL/6 mice (Smith et al., 1985).

\section{Antigenic and idiotypic interactions in the selection of secondary response antibodies}

How can the dominance of rare B cell clones in the secondary antibody response be explained? One possibility is that they are selected at the expense of the primary response clones on the basis of a higher affinity for the antigen, or the potential for higher affinity through somatic mutations (Berek et al., 1985; Manser et al., 1985). The extensive variability of the secondary response antibodies at the $3^{\prime}$ end of CDR3 argues against this interpretation.

A second mechanism potentially involved in the selection of the secondary response rests on the assumption that, in the idiotypic network (Jerne, 1974), every B-cell clonotype can occupy a certain maximum space, controlled by idiotype suppression. Consequently, clones arising in the system at high frequency (and thus dominating the primary response) will expand only moderately upon antigenic stimulation and therefore have little chance to generate high-affinity mutants. Clones occurring at low frequency are allowed substantial clonal expansion, in the course of which mutants producing high-affinity anti-NP antibodies are generated and dominate the secondary response. An implication of this model in the present system is that structures in CDR3 by which the primary response antibodies are distinguished from those of the secondary response are important for the recognition of a 'clonotype' in the idiotypic network. This notion is supported by experimental evidence in this and other idiotypic systems (Rajewsky and Takemori, 1983; Pollock and Kearney, 1984; Cumano and Rajewsky, 1985; Radbruch et al., 1985).

Idiotype control of this type would help the immune system to display in a response its full potential in terms of binding sites. Obviously, in responses with an extremely restricted repertoire, such as the anti-arsonate response (Capra and Nisonoff, 1979), such control mechanisms cannot be seen (Wysocki et al., 1986).

Failure to detect mutant selection through idiotype suppression Idiotype suppression might in addition provide a general mechanism, by which somatic antibody mutants are selected through suppression of the wild-type. Such a mechanism could operate in the pre-immune repertoire, generating mutants before contact with antigen, and/or in the course of an antigen-driven immune response. In the latter case, idiotype suppression would mainly serve the purpose of preventing terminal differentiation into plasma cells, allowing antigen to drive the target B cell into a pathway of proliferation - a prerequisite for mutant selection. Suppression of this type could be exerted by regulatory $\mathrm{T}$ cells, which have indeed been shown to be involved in chronic idiotype suppression (see Rajewsky and Takemori, 1983) and to control antibody secretion (Milburn et al., 1984) and, in a general way, the generation of B-cell memory. Regulatory $\mathrm{T}$ cells could be particularly efficient in mutant selection if they themselves would trigger the hypermutation mechanism in B cells.

In order to test these possibilities, the secondary response antibodies analyzed in this study and the primary response antibodies previously investigated (Cumano and Rajewsy, 1985) were isolated from animals chronically suppressed for the expression of a particular subset of antibodies (subset $a$; Takemori and Rajewsky, 1984), characterized by a TACG sequence at the $V_{H}-D$ border (see Figure 4). This sequence leads to an 'insertion' of an aspartic acid in position 100 of the $\mathrm{H}$ chain. The aspartic acid residue is essential for the recognition of subset $a$ antibodies by both anti-idiotypic antibodies and regulatory $\mathrm{T}$ cells (Cumano and Rajewsky, 1985) which are believed to control the suppressed state.

The predictions are as follows: if idiotype suppression is directly involved in the selection of mutants escaping suppression in the pre-immune repertoire, mutant antibodies carrying a TACG sequence, or a variation of it, at the $\mathrm{V}_{\mathrm{H}}-\mathrm{D}$ border should appear 
in the primary response. If suppression is involved in the generation of mutated secondary response antibodies binding antigen with high affinity, then antibodies resembling primary response antibodies and carrying a TACG sequence at the $\mathrm{V}_{\mathrm{H}}-\mathrm{D}$ border should be selected in the secondary response. In structural terms, these predictions are based on previous work showing that NPbinding antibodies which have lost the idiotypic characteristics of subset $a$ can be generated from subset $a$ antibodies by single point mutation (Radbruch et al., 1985). It might be argued that, in the case of the secondary response, subset $a$ antibodies could not be available for selection in neonatally suppressed animals. However, assuming that the entire population of primary response clones is suppressed in the course of memory generation (see above), the mutant selection model would predict the appearance of mutated primary response antibodies beyond those of subset $a$ in the secondary response.

Clearly, the data in Figure 5 do not fulfil either of the two predictions. Thus, while T-cell-mediated idiotype suppression may still select somatic mutants in the immune system to some extent, it does not appear to be a major driving force in mutant selection.

\section{Materials and methods}

$N P$-specific hybridomas and antibodies

C57BL/6 mice from our colony were injected within $24 \mathrm{~h}$ of birth with $100 \mu \mathrm{g}$ Ac38 antibody as described previously (Takemori and Rajewsky, 1984). At the age of 15 weeks the mice were immunized with $100 \mu \mathrm{g}$ of alum-precipitated NPCG (Imanishi and Mäkelä, 1973) and allowed to rest for 5 weeks before being boosted with $20 \mu \mathrm{g}$ soluble NP-CG. Three days after boosting, spleen cells from three individual mice were fused to the myeloma cell line X63.Ag8.653 (Kearney et al., 1979). The fusion, screening and cloning procedures have been described previously (Cumano and Rajewsky, 1985).

Measurement of antibody affinity

Antibody affinities for the haptens NIP and NP were determined by a method described by Herzenberg $e t$ al. (1980). Details of the adaptation of this method to the NP system have been described (Cumano and Rajewsky, 1985). Briefly, wells of plastic plates were coated with NIP4-BSA, NIP15-BSA, NP8-BSA, NP14-BSA at a concentration of $35 \mu \mathrm{g} / \mathrm{ml}$. The plates were saturated with BSA $(10 \mathrm{mg} / \mathrm{ml})$, at $4^{\circ} \mathrm{C}$ overnight. Serial dilutions of the monoclonal antibody were applied to the plates in triplicate followed by an incubation of $3 \mathrm{~h}$ at room temperature. After extensive washing, specific binding of ${ }^{125}$ I-labelled anti- $\lambda 1$ antibody Ls136 was counted in a gamma counter. The affinity for hapten of the mAb was read from the standard curve generated by the previously determined affinities of the following antibodies: B1-48, $K=4.5 \times 10^{-7}$ for NIP and $5.4 \times 10^{-6}$ for NP, NIG9 $K=10^{-7}$ for NIP and $2 \times 10^{-6}$ for NP, S43 $K_{\mathrm{a}}=2.4 \times 10^{-8}$ for NIP and $2.8 \times 10^{-7}$ for NP.

Isolation of poly $(A)^{+} R N A$

Total RNA of the hybridoma cell lines was isolated as described previously (Siekevitz et al., 1983) and poly(A) ${ }^{+}$RNA was enriched by passing total RNA over an oligo(dT) column (Edmonds et al., 1971).

mRNA sequencing

Poly $(\mathrm{A})^{+}$RNA was directly sequenced using synthetic oligonucleotide primers specific for certain regions of the mRNA to initiate reverse transcription (Cumano and Rajewsky, 1985). Sequences were determined by denaturing polyacrylamide gel electrophoresis. Confirmation of the sequences was achieved by performing sequence reactions with both $\left.{ }^{32} \mathrm{P}\right] \mathrm{ATP}$ and $\left.{ }^{32} \mathrm{P}\right] \mathrm{CTP}$.

Southern blot analysis

Genomic DNA isolated from the hybridoma cell lines and from C57BL/6 liver was digested with the restriction enzymes EcoRI, HindIII and XbaI (Boehringer Mannheim GmbH, Mannheim, FRG), separated on agarose gels and blotted (Southern, 1975: Wahl et al., 1980). The nitrocellulose filters were hybridized with a $\mathbf{J}_{\mathrm{H}_{3-4}}$ probe (a gift of M.Boersch-Supan), labelled with [32P]ATP by nick translation. Filters were exposed to Kodak XAR.5 film at $-70^{\circ} \mathrm{C}$.

\section{Acknowledgements}

We are grateful to D.Allen, Å.Böhm, R.Dildrop, U.Krawinkel, U.Ringeisen, F.Sablitzky, E.Siegmund, T.Simon and other colleagues for technical advice and/or valuable discussion. This work was supported by the Deutsche Forschungsgemeinschaft through SFB 74 and the Heinrich Hertz Stiftung through a grant to A.C.

\section{References}

Berek,C., Griffiths,G.M. and Milstein,C. (1985) Nature, 31, 412-418.

Blankenstein,T., Zoebelien,G. and Krawinkel,U. (1984) Nucleic Acids Res., 12, 6887-6899.

Blomberg,B. and Tonegawa,S. (1982) Proc. Natl. Acad. Sci. USA, 79, 530-533. Boersch-Supan,M.E., Agarwal,S., White-Scharf,M.E. and Imanishi-Kari,T. (1985) J. Exp. Med., 161, 1272-1292.

Bothwell,A.L.M. (1984) In Green,M.I. and Nisonoff,A. (eds), The Biology of Idiotype. Plenum Press, New York, pp. 19-34.

Bothwell,A.L.M., Paskind,M., Reth,M., Imanishi-Kari,T., Rajewsky,K. and Baltimore,D. (1981) Cell, 24, 625-637.

Bothwell,A.L.M., Paskind,M., Reth,M., Imanishi-Kari,T., Rajewsky,K. and Baltimore,D. (1982) Nature, 298, 380-382.

Capra,J.D. and Nisonoff,A. (1979) J. Immunol., 123, 279-283.

Cook,W.D. and Scharff,M.D. (1977) Proc. Natl. Acad. Sci. USA, 74, 56875691.

Cumano,A. and Rajewsky,K. (1985) Eur. J. Immunol., 15, 512-520.

Davies,D.R. and Metzger,H. (1983) Ann. Rev. Immunol., 1, 87-117.

Dildrop,R. (1984) Immunol. Today, 5, 85-88.

Dildrop,R., Brüggemann,M., Radbruch,A., Rajewsky,K. and Beyreuther,K. (1982) EMBO J., 1, 635-640.

Edmonds,M., Vaughan,M.H., Jr and Nakasato,H. (1971) Proc. Natl. Acad. Sci. USA, 68, 1336-1339.

Gearhart,P., Johnson,N.D., Douglas,B. and Hood,L. (1981) Nature, 291, 29-34.

Griffiths,G.M., Berek,C., Kaartinen,M. and Milstein,C. (1984) Nature, 312, $271-275$.

Herzenberg,L.A., Black,S.J., Tokuhisa,T. and Herzenberg,L.A. (1980) J. Exp. Med., 151, 1071-1087.

Imanishi,T. and Mäkelä,O. (1973) Eur. J. Immunol., 3, 323-330.

Jack,R.S., Imanishi-Kari,T. and Rajewsky, K. (1977) Eur. J. Immunol. , 8, 559565.

Jerne,N.K. (1974) Ann. Immunol., 125C, 373-389.

Kearney,J.F., Radbruch,A., Liesegang,B. and Rajewsky,K. (1979) J. Immunol., $123,1548-1550$

Krawinkel,U., Zoebelein,G., Brüggemann,M., Radbruch,A. and Rajewsky,K. (1983) Proc. Natl. Acad. Sci. USA, 80, 4997-5001.

Krawinkel,U., Zoebelein,G. and Bothwell,A.L.M. (1986) Nucleic Acids Res., 14, 3871-3882.

Kurosawa,Y. and Tonegawa,S. (1982) J. Exp. Med., 155, 201-218.

Loh,D.Y., Bothwell,A.L.M., White-Scharf,M.E., Imanishi-Kari,T. and Baltimore,D. (1983) Cell, 33, 85-93.

Maizels,N. and Bothwell,A.L.M. (1985) Cell, 43, 715-720.

Mäkelä,O. and Karjalainen,K. (1977) Immunol. Rev., 34, 119-128.

Manser,T., Wysocki,L.J., Gridley,T., Near,R.I. and Gefter,M.L. (1985) Immunol. Today, 6, 94-101.

McKean,D., Hüppi,K., Bell,M., Staudt,L., Gerhard,W. and Weigert,M. (1984) Proc. Natl. Acad. Sci. USA, 81, 3180-3184.

Milburn,G.L., Parslow,T.G., Goldenberg,C., Granner,D.K. and Lynch,R.G. (1984) J. Mol. Cell. Immunol., 1, 115-123.

Novotny,J. and Haber,E. (1985) Proc. Natl. Acad. Sci. USA, 82, $4592-4596$. Ohno,S., Mori,N. and Matsunaga,T. (1985) Proc. Natl. Acad. Sci. USA, 82, 2945-294?

Pech,M., Höchtl,J., Schnell,H. and Zachau,H.G. (1981) Nature, 291, 668-670.

Pollock,B.A., Kearney,J.F., Vakil,M. and Perry,R.P. (1984) Nature, 311, 376379.

Radbruch,A., Zaiss,S., Kappen,C., Brüggemann,M., Beyreuther,K. and Rajewsky,K. (1985) Nature, 315, 506-508.

Rajewsky,K. and Takemori,T. (1983) Annu. Rev. Immunol., 1, 569-607.

Reth,M., Hämmerling, G.J. and Rajewsky,K. (1978) Eur. J. Immunol., 8, 393 400.

Reth,M., Bothwell,A.L.M. and Rajewsky,K. (1981) In Janeway,C., Sercarz,E.E. and Wigzell,H. (eds), Immunoglobulin Idiotypes: ICN-UCLA Symposia on Molecular and Cellular Biology, Vol. XX. Academic Press Inc., New York, pp. 169-78.

Reynaud,C-A., Anquez,V., Dahan,A. and Weill,J-C. (1985) Cell, 40, 283-291.

Rudikoff,S., Pawlita,M., Pumphrey,J. and Heller,M. (1984) Proc. Natl. Acad. Sci. USA, 81, 2162-2166.

Sablitzky,F. and Rajewsky,K. (1984) EMBO J., 3, 3005-3012.

Sablitzky,F., Radbruch,A. and Rajewsky,K. (1982) Immunol. Rev., 67, 59-72. Sablitzky,F., Wildner,G. and Rajewsky,K. (1985a) EMBO J., 4, 345-350.

Sablitzky,F., Weisbaum,D. and Rajewsky,K. (1985b) EMBO J., 4, 3435-3437. Schilling,J., Clevinger,B., Davie,J.M. and Hood,L. (1980) Nature, 283, 35-40. 


\section{A.Cumano and K.Rajewsky}

Schiff,C., Milili,M. and Fougereau,M. (1985) EMBO J., 4, 1225-1230.

Siekevitz,M., Huang,S.Y. and Gefter,M.L. (1983) Eur. J. Immunol., 13, 123132.

Smith,F.I., Cumano,A., Licht,A., Pecht,I. and Rajewsky,K. (1985) Mol. Immunol., 22, 1209-1216.

Southern,E.M. (1975) J. Mol. Biol., 98, 503-517.

Szostak,J.W., Orr-Weaver,T.L. and Rothstein,R.J. (1983) Cell, 33, 25-35.

Takemori,T. and Rajewsky,K. (1984) Eur. J. Immunol., 14, 656-667.

Wahl,G.M., Stern,M. and Stark,G.R. (1980) Proc. Natl. Acad. Sci. USA, 76, 3683-3687.

Wysocki,L., Manser,T. and Gefter,M. (1986) Proc. Natl. Acad. Sci. USA, 83, $1847-1851$.

Received on 2 June 1986; revised on 28 July 1986 